\title{
Spatial and Temporal Habitat Use by GPS Collared Male Cheetahs in Modified Bushland Habitat
}

\author{
Matti Nghikembua', Jacob Harris ${ }^{2}$, Tom Tregenza ${ }^{2}$, Laurie Marker ${ }^{1 *}$ \\ ${ }^{1}$ Cheetah Conservation Fund, Otjiwarongo, Namibia \\ ${ }^{2}$ University of Exeter, Penryn Campus, Cornwall, United Kingdom \\ Email: ccfmatti@iway.na, scienceisbeautiful@gmail.com, T.Tregenza@exeter.ac.uk, "cheetah@iway.na
}

Received 24 March 2016; accepted 11 July 2016; published 14 July 2016

Copyright (C) 2016 by authors and Scientific Research Publishing Inc.

This work is licensed under the Creative Commons Attribution International License (CC BY). http://creativecommons.org/licenses/by/4.0/

(c) (i) Open Access

\section{Abstract}

Cheetahs and other apex predators are threatened by human-wildlife conflict and habitat degradation. Bush encroachment creates one of the biggest forms of habitat change, thus it is important to understand the impact this has on habitat use. We investigated habitat preferences of five male cheetahs in Namibian farmlands degraded by bush encroachment. Cheetahs were tracked using satellite based Global System for Mobile (GSM) collars providing a higher resolution on ranging behavior. We aimed to investigate: 1) habitat characteristics; 2) evidence for habitat selection; 3 ) temporal activity partitioning; and 4) whether revisits to locations were related to habitat type. There were differences in habitat characteristics, showing that cheetahs were able to utilise different habitats. Fecal pellet counts revealed that warthog, oryx, scrub hare and kudu were most abundant. The cheetahs spent more time in high visibility shrubland, suggesting they selected rewarding patches within predominantly bush-encroached landscapes. The usage in marginal habitat was strikingly influenced by habitat type, with both previously cleared and open vegetated areas showing high proportions in edge use. Individuals exhibited significant temporal activity partitioning, showing peaks between late afternoon and early morning hours. This finding could be key to managing human-wildlife conflict by showing that increased protection such as the use of herders and livestock guarding dogs should be used as mitigation methods to minimize the impact of cheetah specific temporal patterns at all times as defined in this research. Visits to the same locations were not correlated to habitat type; revisits may be dictated by other reasons such as social interaction, prey density or avoidance of other predators. Findings from this study will help build existing knowledge on the effects bush encroachment has on cheetah habitat preference.

\footnotetext{
*Corresponding author.
} 


\section{Keywords}

\section{Bush Encroachment, Cheetah, Conservation, Land Use Management}

\section{Introduction}

Bush encroachment is a global phenomenon involving the invasion and thickening of aggressive woody species (de Klerk, 2004) in a landscape. This phenomenon is historically well documented in savanna habitats subjected to farmland mismanagement (de Klerk, 2004). Little is understood regarding its consequences towards wildlife, especially carnivores (Broomhall, Mills, \& Toit, 2003; Muntifering et al., 2006; Marker et al., 2008). While bush encroachment is largely seen as a detriment to habitat, it can be controlled (Ward et al., 2000; Moleele et al., 2002; Katjiua \& Ward, 2007). This is true both for protected areas and for privately owned and communal lands which provide refuge for wide-ranging carnivore species.

During the 20th century, the cheetah (Acinonyx jubatus) suffered drastic global population decline due to a myriad of anthropogenic factors and is currently restricted to Africa and Iran (Eaton, 1974; Marker et al., 2007). Consequently, the species appeared on the International Union for Conservation of Nature and Natural Resources (IUCN) Red-List in the 1970s (Eaton, 1974; Kelly \& Durant, 2000; Marker, 2002), with a world population today of less than 6674 mature individuals (Durant et al., 2015). The largest free-ranging population is believed to reside in Namibia, with an estimated 3000 individuals (Marker et al., 2007), of which 90\% resides outside of protected areas, mainly on commercial farmland. This commercial farmland is predominantly stocked with cattle and small livestock (Marker, 2002; Marker et al., 2003b; Marker et al., 2007; Marker et al., 2008).

Approximately 25 million hectares of Namibian farmlands are affected by bush encroachment of which 10 million is considered to be severely encroached (Burke, 2006). These farmlands provide a unique opportunity to study the habitat selection of a large predator in an area where habitats for grazers and predators are degraded (Ben-Shahar, 1992; Jeltsch et al., 1997; Ward et al., 2000; Moleele et al., 2002; Burke, 2006). For example, loss of suitable habitat could reduce hunting efficiency, prey density and distribution (Gros \& Rejmanek, 1999; Broomhall et al., 2003; Marker et al., 2003b; Bissett \& Bernard, 2007; Muntifering et al., 2006; Marker et al., 2007; Marker et al., 2008). Alternatively, bush encroachment may have positive consequences, providing shelter from large predators like lions (Panthera leo) and spotted hyenas (Crocuta crocuta) (Durant, 1998; Durant, 2000a, 2000b; Durant et al., 2004).

We investigated: 1) habitat characteristics overlapping with the collared males' GPS fixes; 2) evidence for habitat selection; 3) temporal activity partitioning; and 4) whether revisits to similar locations were related to habitat type. These analyses will be valuable in identifying and prioritising sites for habitat restoration, protection, reintroductions and tourism, as well as helping livestock farmers better manage their operations to reduce conflict with predators.

\section{Materials and Methods}

\subsection{Study Area}

Cheetahs in this study were distributed over 13 commercial farms around the Waterberg Plateau $\left(20^{\circ} 25^{\prime} 0^{\prime \prime} \mathrm{S}\right.$, $17^{\circ} 13^{\prime} 0$ " E) in north-central Namibia (Figure 1). The most common land-use practices were game ranching and livestock farming, and a combination of both known as integrated livestock and wildlife management called conservancies. The study area receives a mean annual rainfall of $400 \mathrm{~mm}$, with the rainy season occurring between November and April. The overall mean temperature range is $20^{\circ} \mathrm{C}-21^{\circ} \mathrm{C}$ (coldest month: $4^{\circ} \mathrm{C}-6^{\circ} \mathrm{C}$, hottest month: $32^{\circ} \mathrm{C}-34^{\circ} \mathrm{C}$ ). Multiple artificial waterholes allow access to surface water for livestock and wildlife year round (Barnard, 1998). The most prominent geological feature is the Waterberg Plateau, one of Namibia's protected wildlife areas. The region is classified as semi-arid thornbush savanna, dominated by both Blackthorn (Senegalia mellifera) and Sickle bush (Dichrostachys cinerea) woody vegetation (de Klerk, 2004).

\subsection{Distribution Data}

Between September and December 2007, six adult males (two of which make a coalition) were captured at scent 


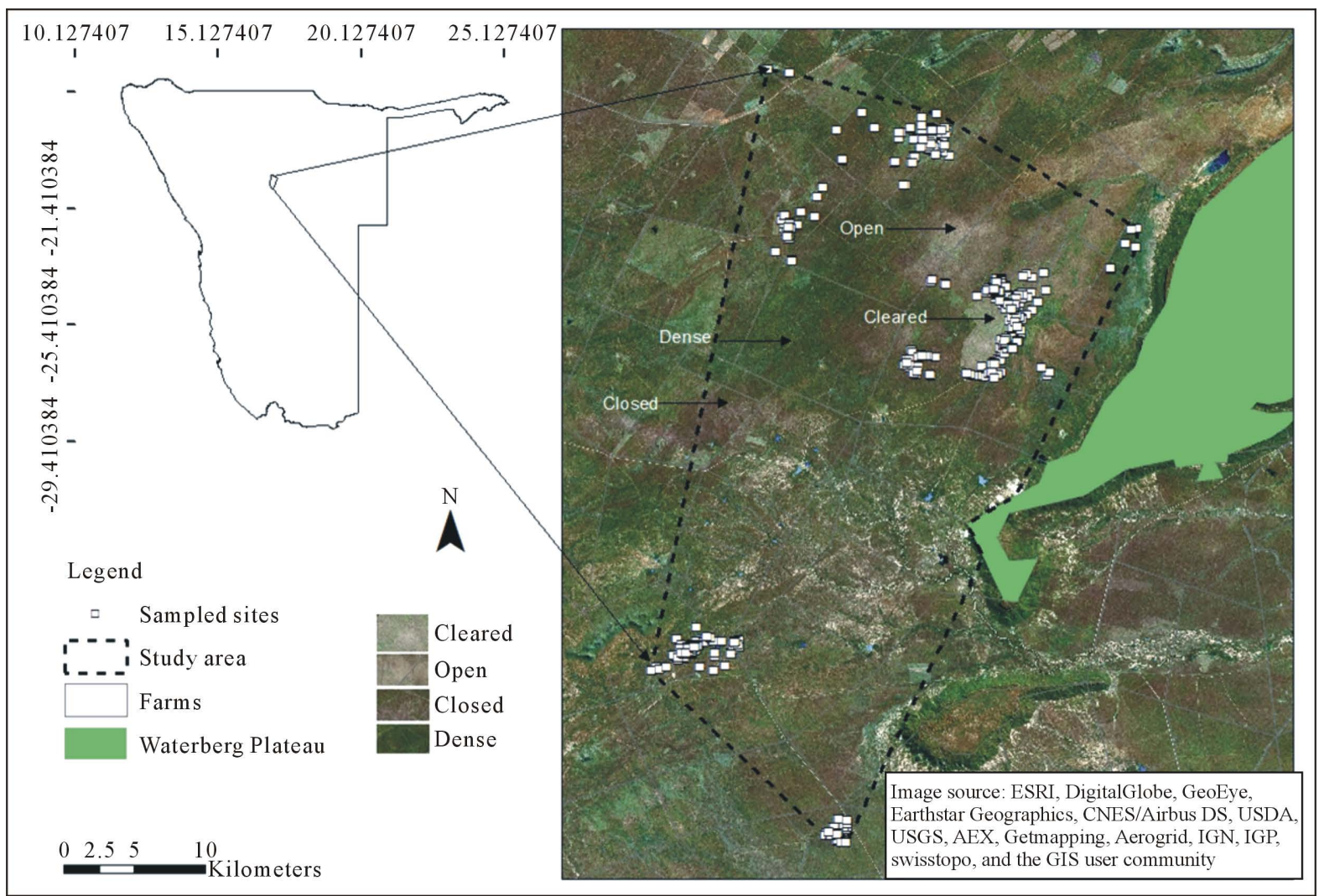

Figure 1. Study area map, indicating surveyed locations for habitat characteristics on north-central commercial farmlands in Namibia.

marking areas (locally known as "play-trees") (Marker-Kraus \& Kraus, 1993) within the Cheetah Conservation Fund (CCF) study area (Table 1) using box traps measuring $3 \mathrm{~m} \times 0.8 \mathrm{~m} \times 0.9 \mathrm{~m}$ (Marker et al., 2003b). Each trap was fitted with 2 doors at each end and had a trigger plate mechanism in the middle of the box. No pheromones or attractants were used as the cheetahs were naturally drawn to "play trees". Upon capture, the cheetahs were transferred into transport/squeeze cage and transported to CCF veterinary clinic for biomedical examinations. Cheetah biomedical examinations follow CCF standard protocols (Marker et al., 2003b). The anesthetic agent (Telazol: Tiletamine HCI and Zolazepan HCI, Fort Dodge, Iowa, USA) was administered intramuscularly in the hind quarters using a hand syringe. Individuals were given a normal dose of $100 \mathrm{mg} / \mathrm{ml}$ with animals showing sedation within $4-6$ minutes and were recumbent within $8-10$ minutes. Individuals were marked with a unique identification number aluminum ear tag and a uniquely numbered concerted transponder (Trovan Electronic identification systems, Model-ID 100) at the base of the tail (Marker et al., 2003b). Five out of six of the individuals were fitted with GPS/GSM collars, as one formed coalition with its brother (Figure 2). The collars (Africa Wildlife Tracking, Rietondale, Pretoria, SA) weighed $650 \mathrm{~g}$, equivalent to $1.3 \%$ of body mass for a 50 $\mathrm{kg}$ male, well below the $3 \%$ recommended limit (Kenward, 2001). All individuals were released at their respective sites of capture. The collars remained fitted for a maximum of nine months after which the cats were recaptured using traps again and the collars removed. GPS data were recorded every three to five hours and consisted of date, time, coordinates (longitude, latitude), temperature, speed, direction and an indication of coverage. The capturing and handling of animals was done in accordance with acceptable procedures and permits (Ministry of Environment and Tourism (MET) collection permit ID 1200/2007).

\subsection{Habitat Characteristics}

We selected 850 locations after the collaring period between April and June 2009 (end of the rainy season and beginning of the dry season) in order to quantify habitat on foot (Figure 1). The locations were extracted from adaptive kernel home ranges. We defined core home-ranges as the $30 \%$ probability utility distributions using 
Table 1. Cheetahs collared and monitored during March and June 2009 using GSM collars. Age estimate in months according to the classification by Marker et al. (2008): $1=$ Newly independent $(>18-30), 2=$ Young adult $(>30-48), 3=$ Prime adult $(>48-96)$ and $4=$ Old adult $(>96-144)$. Social male grouping: Coalition with two individuals $=\mathrm{C}(2)$ and single males $=\mathrm{S}$.

\begin{tabular}{ccccccc}
\hline AJU Number & $\begin{array}{c}\text { Social } \\
\text { grouping }\end{array}$ & Weight $(\mathrm{kg})$ & $\begin{array}{c}\text { Age at initial } \\
\text { collaring }\end{array}$ & $\begin{array}{c}\text { Total days } \\
\text { tracked }\end{array}$ & $\begin{array}{c}\text { Total recorded } \\
\text { fixes }\end{array}$ & $\begin{array}{c}\text { Total fixes } \\
\text { inspected }\end{array}$ \\
\hline 1537 & $\mathrm{C}(2)$ & 51 & 2 & 100 & 203 & 85 \\
1533 & $\mathrm{~S}$ & 57 & 3 & 226 & 1763 & 461 \\
1459 & $\mathrm{~S}$ & 53 & 3 & 67 & 510 & 154 \\
1534 & $\mathrm{~S}$ & 51 & 3 & 83 & 347 & 46 \\
1536 & $\mathrm{~S}$ & 51 & 3 & 112.8 & 669 & 104 \\
All males & Mean & 52.6 & 2.8 & \pm 0.4 & \pm 89 & 170 \\
$(\mathrm{n}=5)$ & $\mathrm{SD}$ & \pm 2.6 & & \pm 64.4 & \pm 627.5 & \pm 167.3 \\
\hline
\end{tabular}

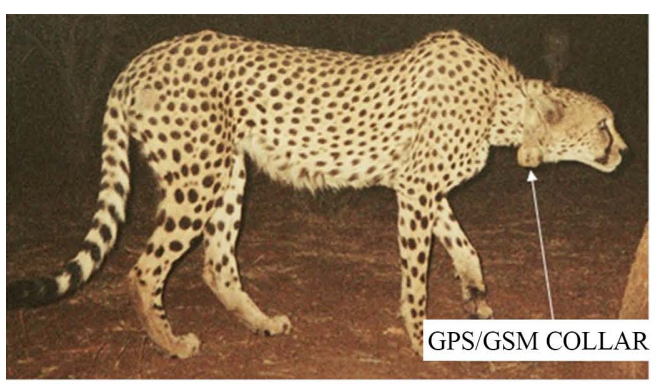

(a)

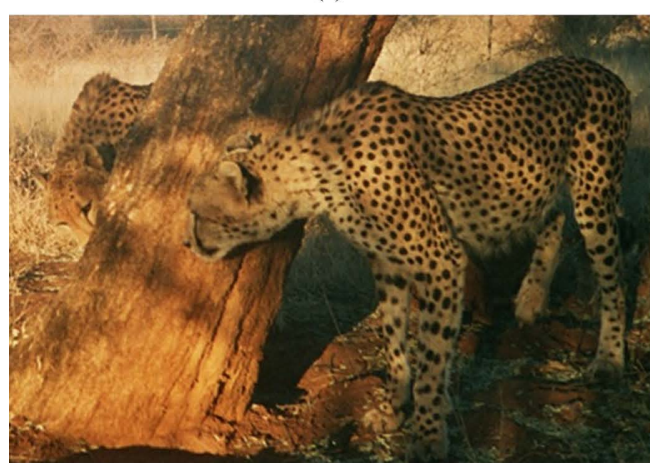

(b)

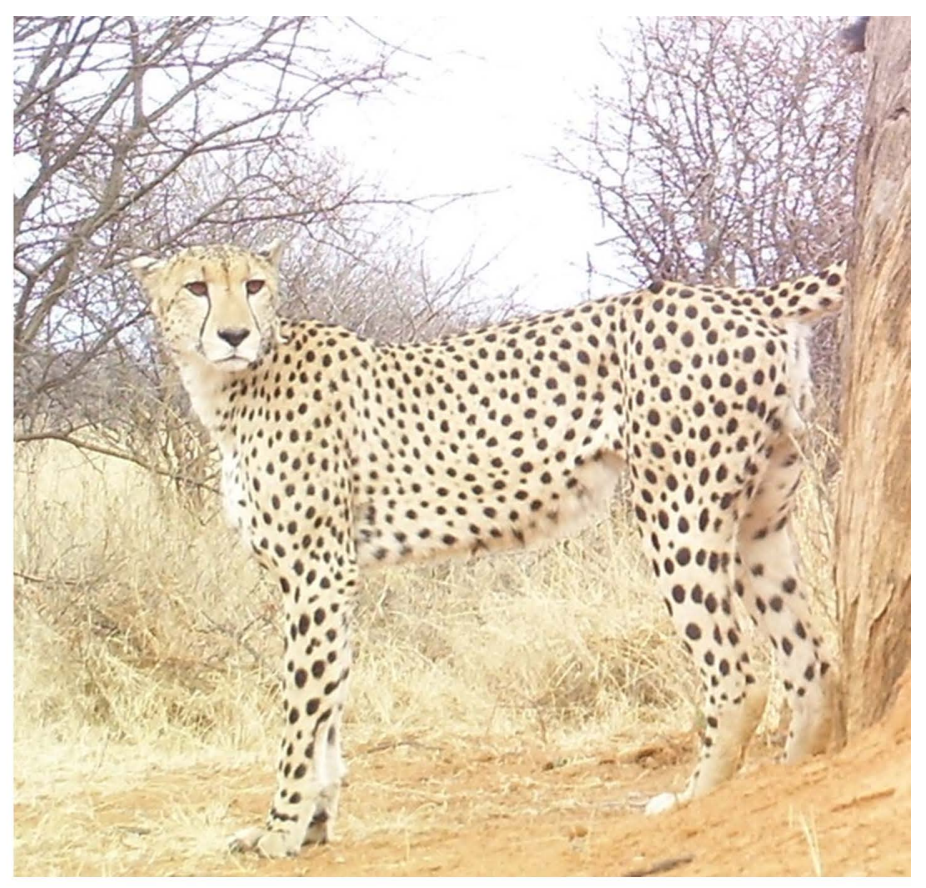

(c)

Figure 2. Single and coalition male cheetah social groups within the study area. Cheetah Conservation Fund trap camera photos. (a) Single male (AJU 1533); (b) Coalition males; (c) AJU 1537 (C2).

similar approaches as Muntifering et al. (2006). We estimated those parameters using ArcView 3.2, Arc GIS 9.3 (ESRI, Redlands, CA, USA) and the Animal Movement extension (Hooge, Eichenlaub, \& Solomon, 1999). Clustered observations with a $10-\mathrm{m}$ accuracy were thinned out selecting a single location through the creation of random point theme and distance matrix extensions within ArcView 3.2.

Habitat characteristics were quantified representing cheetah habitat selection criteria (Caro, 1994; Marker, 2002; Muntifering et al., 2006). These included: 1) Thorn bush habitat classification (open thorn bush savanna $\leq 30 \%$, medium/intermediate thorn bush $>30 \%-75 \%$, dense thorn bush $>75 \%$; and previously cleared field); 2 ) sighting visibility: measured by an observer at the center of a plot crouched at $65 \mathrm{~cm}$ height above-ground to simulate the average eye height of a cheetah as in Muntifering et al. (2006). A second person then walked away from the observer in a randomised compass bearing until they could not be seen. Distance was then measured using a one-meter accuracy rangefinder (Bushnell Yardage Pro Scout $6 \times$ ). This process was repeated three times, 
adding a subsequent $90^{\circ}$ to the previous bearing; 3) tree/shrub height: measured using a marked rule polyvinyl chloride (PVC) pipe three meters in height (10-cm accuracy) within a six meter radius $\left(113.14 \mathrm{~m}^{2}\right)$ circular plot; 4) tree/shrub density: measured by counting all individual tree/shrubs present within a six meter radius (individuals $/ \mathrm{m}^{2}$ ); and 5) for prey fecal pellet presence/absence as qualitative indicator of prey species habitat use (Brock, Nortje, \& Gaigher, 2003; Muntifering et al., 2006) within a six meter radius. Cheetah and prey fecal pellet observations were recorded only if they were dark/wet with a glossy patina, or dark/dry, with the assumption that paler pellets were older (Hilbert et al., 2010). In addition, pellet groups with signs of advanced decay (e.g. insect activity) or those non-intact (scattered and crumbled) were avoided. We recorded fecal pellets presence/absence both in groups and middens (i.e. more than six pellet groups within a meter from each other (Brock, Nortje, \& Gaigher, 2003).

It should be noted that habitat characteristics were quantified six months from the date of the last GPS/GSM fix recording and that seasonal effects could influence results. Rainfall within the study period was similar (NMS, 2012). The study area fell within a semi arid zone and the recruitment of woody seedlings is extremely episodic. At least two to three consecutive above average rainfall seasons are required for successful seedling establishment, specifically for the dominant Senegalia mellifera species (Zimmerman, 2009; Rothaughe, 2011). High levels of browsing and grazing by wildlife are capable to alter vegetation structure and composition in African savannas (de Klerk, 2004). However, these regimes were replaced with domestic livestock, which places more pressure on the grassy component. Consequently, most Namibian farmlands are overgrazed, resulting in a thickened bush structure with little combustible material, which limits high intensity fires. In addition, common large browsers present in the study area such as eland (Tragelaphus oryx) and kudu (Tragelaphus strepsiceros) would have no effect on density and structure of mature woody plants other than on seedling survival whereas fires are being suppressed (de Klerk, 2004).

Therefore, we expect that there should be no differences in woody vegetation density and structure from the period the fixes were recorded and quantified given this short time lapse. An increase in foliage and grass production towards the end of the growing season may reduce the habitat visibility estimates in comparison to the dry season when most leaves fall off trees. Therefore, data obtained were considered a conservative estimate of sighting visibility of each habitat. Due to the creation of permanent water resources and erection of fences, most Namibian game are resident and do not pursue migrations as before (Barnard, 1998). Thus, it was expected that game populations remained relatively constant between the seasons within the nine-month collaring period. This study recognizes the importance of inter-seasonal differences and variations and would suggest timely quantifications for more accurate information in future studies.

\subsection{Statistics}

Data were analyzed using SPSS (version 12.0.1 SPSS Inc., Chicago, USA) and ArcView GIS (Version 9.3, Redlands, California, USA). Normality was tested using the Kolmogorov-Smirnov test (Norušis, 2000; Tredoux \& Durrheim, 2002). Bootstrap techniques were used to estimate error and confidence intervals of all key habitat characteristics using 1000 simulations (Southwood \& Henderson, 2000; Tredoux \& Durrheim, 2002). A Kruskal-Wallis test was used to compare characteristics of different habitats (Brower et al., 1998; Muntifering et al., 2006). Relationships between habitat characteristics were calculated using two-tailed Spearman's rank correlation coefficients $(r)$. We used Chi square goodness-of-fit tests to determine significant departures from the expected (based on random habitat use) frequency of visits to the different habitats (Marker, 2002). Temporal activity partitioning between day periods were calculated from evidence provided by the GPS fixes showing trip/travel speed from the time locations were recorded. We classified fixes based on trip/travel speed on a presence/absence basis i.e., motion based activity (active $=1$, inactive $=0$ ), and with any speed $\geq 1$ recorded being classified as active. All GSM positions whose speed-readings were equal to zero were considered to correspond to inactivity (i.e. resting or stationery). Time data recorded by the GSM collars were grouped into four time periods which coincided with peaks in cheetah activity observed within the study area: 1) midnight—early morning (00:01 - 06:00), 2) early morning — noon (06:01 - 00:00), 3), noon—late afternoon (00:01 - 18:00), and 4) late afternoon - midnight (18:01 - 00:00). In addition, activity was grouped into eight moon phases: New moon, First quarter, Full moon, Last quarter, New moon-First quarter, first quarter-full moon, Full moon-Last quarter, Last quarter-New moon. We used cross classification chi-square cross tab's, with adjusted $\mathrm{p}$ value (Bonferroni methods) test to calculate the proportion of fixes indicating motion (active/inactive) between the 
day periods and moon phases.

We investigated non-randomness due to the occurrence of multiple visits to similar locations $(\geq 10 \mathrm{~m}$ from core fixes) by measuring the degree of over-dispersion per habitat. To prevent temporal clumping of multiple revisits at similar locations on similar days, only a single occasion per day was included to ensure independence of observations. A Poisson distribution with the variance equal to the mean was used to describe the standard null assumption of a random distribution of visits. An index of dispersion, $I_{D}=(n-1)$ (variance/mean), which has a $\chi^{2}$ distribution with $\mathrm{n}-1$ degrees of freedom was calculated for each habitat.

\section{Results}

\subsection{Habitat Characteristics}

Sighting visibility differed significantly across the four habitats. Higher median scores for sighting visibility were recorded in the cleared field $(M d=87.4)$ and open $(M d=52.0)$ than the closed $(M d=19.0)$ and dense $(M d$ $=13.5$ ) shrublands (Table 2). Tree/shrub density differed significantly amongst the four habitats (Table 2 ). The dense shrubland had a higher median score for vegetation density $(M d=16)$ than the other habitats $(M d$ : cleared $=15.5$, closed $=12$ and open $=9)($ Table 2$)$. Tree/shrub heights differed significantly amongst the four habitats. Median values for the dense shrublands $(M d=1.84)$ and closed shrublands $(M d=1.66)$ were higher, than the open $(M d=1.1)$ and cleared $(M d=0.91)$ habitats. There was a negative correlation between sighting visibility and vegetation heights $(r=-0.552, \mathrm{n}=522, p<0.01)$ and sighting visibility and vegetation density $(r=-0.27, \mathrm{n}$ $=522, p<0.01$.

Eight common prey species were identified in the survey site with the most fecal pellet presence being of warthog (Phacochoerus africanus), oryx (Oryx gazella) scrub hare (Lepus saxatilis) and kudu (Tragelaphus strepsiceros) (Table 2). The presence of oryx and red hartebeest (Alcelaphus buselaphus caema) fecal pellets were significantly higher in the previously cleared fields. In addition, the presence of scrub hare fecal pellets was significantly highest in the dense and open habitat (Table 2). No significant differences $(p>0.05)$ were detected in the proportion of plots found with warthog, duiker (Sylvicapra grimmia), eland (Tragelaphus oryx), kudu (Tragelaphus strepsiceros), and steenbok (Raphicerus campestris) fecal pellets amongst the four habitats. Relative species richness based on the presence/absence of fecal pellets did not differ significantly across the four habitats.

Table 2. Habitat characteristic measured in the different habitats (Mean $\pm \mathrm{SD})$ and prey presence in different habitat.

\begin{tabular}{|c|c|c|c|c|c|c|c|}
\hline \multirow{2}{*}{ Habitat characteristics } & \multicolumn{4}{|c|}{ Habitat } & \multicolumn{3}{|c|}{ Statistics } \\
\hline & Closed & Dense & Cleared field & Open & $\chi^{2}$ & df & $P$ \\
\hline Visibility (meters m.) & $22.3 \pm 11.5$ & $14.9 \pm 6.6$ & $96.7 \pm 51.3$ & $71 \pm 54.6$ & 255.9 & 522 & $<0.01$ \\
\hline Tree/shrubs Height (m.) & $1.7 \pm 0.5$ & $1.9 \pm 0.5$ & $1 \pm 0.5$ & $1.3 \pm 0.9$ & 159 & 522 & $<0.01$ \\
\hline Tree/shrub Density per $\left(113.14 \mathrm{~m}^{2}\right)$ & $18.1 \pm 9.6$ & $18.1 \pm 9.6$ & $10.4 \pm 7.3$ & $14.1 \pm 7.8$ & 66.2 & 522 & $<0.01$ \\
\hline \multicolumn{8}{|l|}{ Prey fecal pellet presence } \\
\hline Warthog & $36.5 \% \mathrm{a}_{\mathrm{a}}$ & $38.8 \% \mathrm{a}_{\mathrm{a}}$ & $37.5 \% \mathrm{a}_{\mathrm{a}}$ & $39.3 \% \mathrm{a}_{\mathrm{a}}$ & 2.88 & 3 & 0.4 \\
\hline Oryx & $32.4 \% \mathrm{a}_{\mathrm{a}}$ & $18.8 \% \mathrm{a}$ & $56.2 \%$ b & $20.7 \% \mathrm{a}$ & 27.73 & 3 & $<0.01$ \\
\hline Shrub hare & $14.3 \% \mathrm{a}_{\mathrm{a}}$ & $27.1 \%$ b & $2.1 \% \mathrm{a}$ & $15.2 \% \%_{\mathrm{a}, \mathrm{b}}$ & 15.51 & 3 & $<0.01$ \\
\hline Kudu & $12.3 \% \mathrm{a}_{\mathrm{a}}$ & $10.6 \% \mathrm{a}$ & $10.4 \% \mathrm{a}_{\mathrm{a}}$ & $13.8 \% \mathrm{a}_{\mathrm{a}}$ & 0.69 & 3 & 0.88 \\
\hline Red hartebeest & $5.7 \%_{\mathrm{a}, \mathrm{b}, \mathrm{c}}$ & $2.4 \%_{\mathrm{c}}$ & $16.7 \%_{\mathrm{b}}$ & $2.1 \%_{\mathrm{a}, \mathrm{c}}$ & 17.31 & 3 & $<0.01$ \\
\hline Steenbok & $4.1 \% \mathrm{a}$ & $4.7 \% \mathrm{a}$ & & $4.8 \% \mathrm{a}$ & 2.36 & 3 & 0.50 \\
\hline Eland & $2.5 \% \%_{\mathrm{a}}$ & $2.4 \% \mathrm{a}_{\mathrm{a}}$ & $8.3 \%_{\mathrm{a}}$ & $3.4 \% \%_{a}$ & 4.66 & 3 & 0.20 \\
\hline Duiker & & $1.2 \% \mathrm{a}$ & & $0.7 \% \mathrm{a}$ & & & \\
\hline Per habitat & $52.9 \% \%_{\mathrm{a}, \mathrm{b}}$ & $55.3 \% \%_{\mathrm{a}, \mathrm{b}}$ & $70.8 \%$ b & $44.1 \% \%_{a}$ & 10.8 & 3 & $<0.01$ \\
\hline
\end{tabular}

Each subscript letter denotes a subset of Habitat categories whose column proportions do not differ significantly from each other at the 0.05 level. 


\subsection{Habitat Preference}

Overall, the tracked cheetahs showed significant preference towards the open shrubland $\left(\chi^{2}=16.54, p<0.01\right)$ and the cleared field $\left(\chi^{2}=12.06, p<0.01\right)$ in proportion to their availability (Figure 3). Overall, the proportion of fixes observed in the open habitat was high along habitat margins (Table 3). Visits to the closed shrubland did not reveal any significant preference in approximate proportion to its availability $\left(\chi^{2}=1.33, p=0.25\right)$, whereas dense shrubland was significantly avoided $\left(\chi^{2}=42.05, p<0.01\right)$.

\subsection{Temporal Activity Partitioning and Multiple Visits}

The proportion of motion based activity patterns differed significantly between the day periods $\left(\chi^{2}=48.68, \mathrm{df}=\right.$ $3, p<0.01$ ). High activity was observed between late afternoon to early morning hours (Figure 4). Motion based activity was slightly higher during the full moon and new moon-first quarter phases and lowest in the last quarter; however results were statistically insignificant to warrant conclusions (Table 4).

Table 3. Tabulation of the presence/absence of GSM fixes found in proximity to habitat edges per habitat type.

\begin{tabular}{|c|c|c|c|c|c|c|}
\hline & & \multicolumn{4}{|c|}{$\%$ within Habitat } & \multirow{2}{*}{ Total } \\
\hline & & Closed & Dense & Cleared field & Open & \\
\hline \multirow{2}{*}{ Habitat edge } & Present & $20.9 \% \mathrm{o}_{\mathrm{a}}$ & $14.1 \% \mathrm{a}$ & $29.2 \% \%_{\mathrm{a}, \mathrm{b}}$ & $41.4 \% \mathrm{~b}$ & $26.2 \%$ \\
\hline & Absent & $79.1 \% \%_{a}$ & $85.9 \% \mathrm{a}$ & $70.8 \%_{\mathrm{a}, \mathrm{b}}$ & $58.6 \% \mathrm{~b}$ & $73.8 \%$ \\
\hline \multicolumn{2}{|c|}{ Total } & $100.0 \%$ & $100.0 \%$ & $100.0 \%$ & $100.0 \%$ & $100.0 \%$ \\
\hline
\end{tabular}

Each subscript letter denotes a subset of Habitat categories whose column proportions do not differ significantly from each other at the 0.05 level.

Table 4. Tabulation of the presence/absence of GSM fixes showing active motion according to moon phase.

\begin{tabular}{|c|c|c|c|c|c|c|c|c|c|c|}
\hline & & \multicolumn{8}{|c|}{$\%$ within moon phases } & \multirow[b]{2}{*}{ Total } \\
\hline & & $\begin{array}{l}\text { New } \\
\text { Moon }\end{array}$ & $\begin{array}{l}\text { First } \\
\text { quarter }\end{array}$ & $\begin{array}{l}\text { Full } \\
\text { moon }\end{array}$ & $\begin{array}{l}\text { Last } \\
\text { quarter }\end{array}$ & $\begin{array}{l}\text { New moon- } \\
\text { First quarter }\end{array}$ & $\begin{array}{c}\text { First } \\
\text { quarter- } \\
\text { Full moon }\end{array}$ & $\begin{array}{l}\text { Full moon- } \\
\text { Last quarter }\end{array}$ & $\begin{array}{c}\text { Last } \\
\text { quarter- } \\
\text { New moon }\end{array}$ & \\
\hline \multirow{2}{*}{ Activity } & Active & $14.1 \% \mathrm{a}_{\mathrm{a}}$ & $14.1 \%_{\mathrm{a}}$ & $15.9 \%_{\mathrm{a}}$ & $9.1 \%$ & $15.4 \% \mathrm{a}$ & $14.7 \% \mathrm{a}_{\mathrm{a}}$ & $12.5 \% \mathrm{a}$ & $12.8 \% \%_{\mathrm{a}}$ & $13.8 \%$ \\
\hline & Inactive & $85.9 \% \%_{\mathrm{a}}$ & $85.9 \% \%_{\mathrm{a}}$ & $84.1 \%_{\mathrm{a}}$ & $90.9 \% \%_{a}$ & $84.6 \% \mathrm{a}_{\mathrm{a}}$ & $85.3 \% \mathrm{o}_{\mathrm{a}}$ & $87.5 \% \mathrm{a}_{\mathrm{a}}$ & $87.2 \% \mathrm{a}_{\mathrm{a}}$ & $86.2 \%$ \\
\hline \multicolumn{2}{|c|}{ Total } & $100.0 \%$ & $100.0 \%$ & $100.0 \%$ & $100.0 \%$ & $100.0 \%$ & $100.0 \%$ & $100.0 \%$ & $100.0 \%$ & $100.0 \%$ \\
\hline
\end{tabular}

Each subscript letter denotes a subset of Moon phase categories whose column proportions do not differ significantly from each other at the 0.05 level.

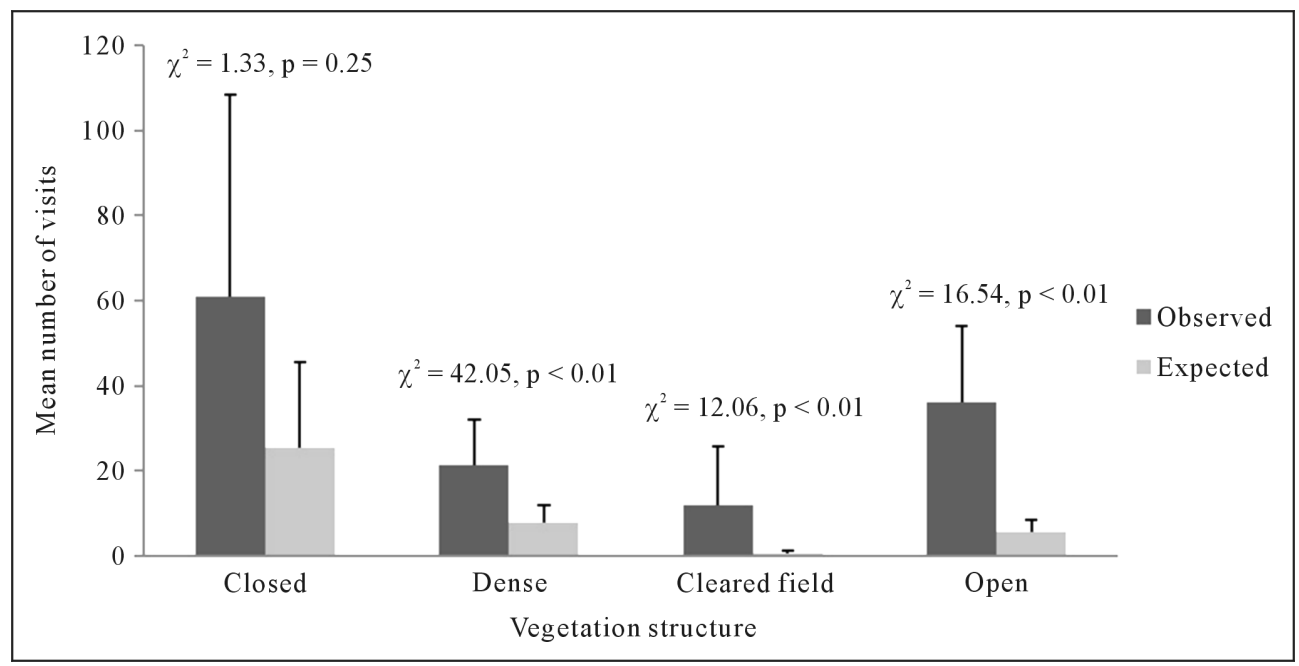

Figure 3. Observed and expected cheetah visits showing significant deviations from expected ratios in the open, closed, dense and cleared habitats. 
Cheetahs had a tendency to revisit locations on different days; however, such visits were not spatially contiguous across all habitats $\left(\mathrm{I}_{\mathrm{D}}\right.$ : open $=145.2, p=0.90$; closed $=281.5, p=0.73$; dense $=136.6, p=0.24$; cleared $=$ 48.6, $p=0.96$ ). This is further confirmed by the graphical examination in observed vs. expected probability of occurrence scores between independent visits to similar locations. From this, we concluded that visits to similar locations followed a random distribution with a slight tendency towards uniform dispersion (Figure 5).

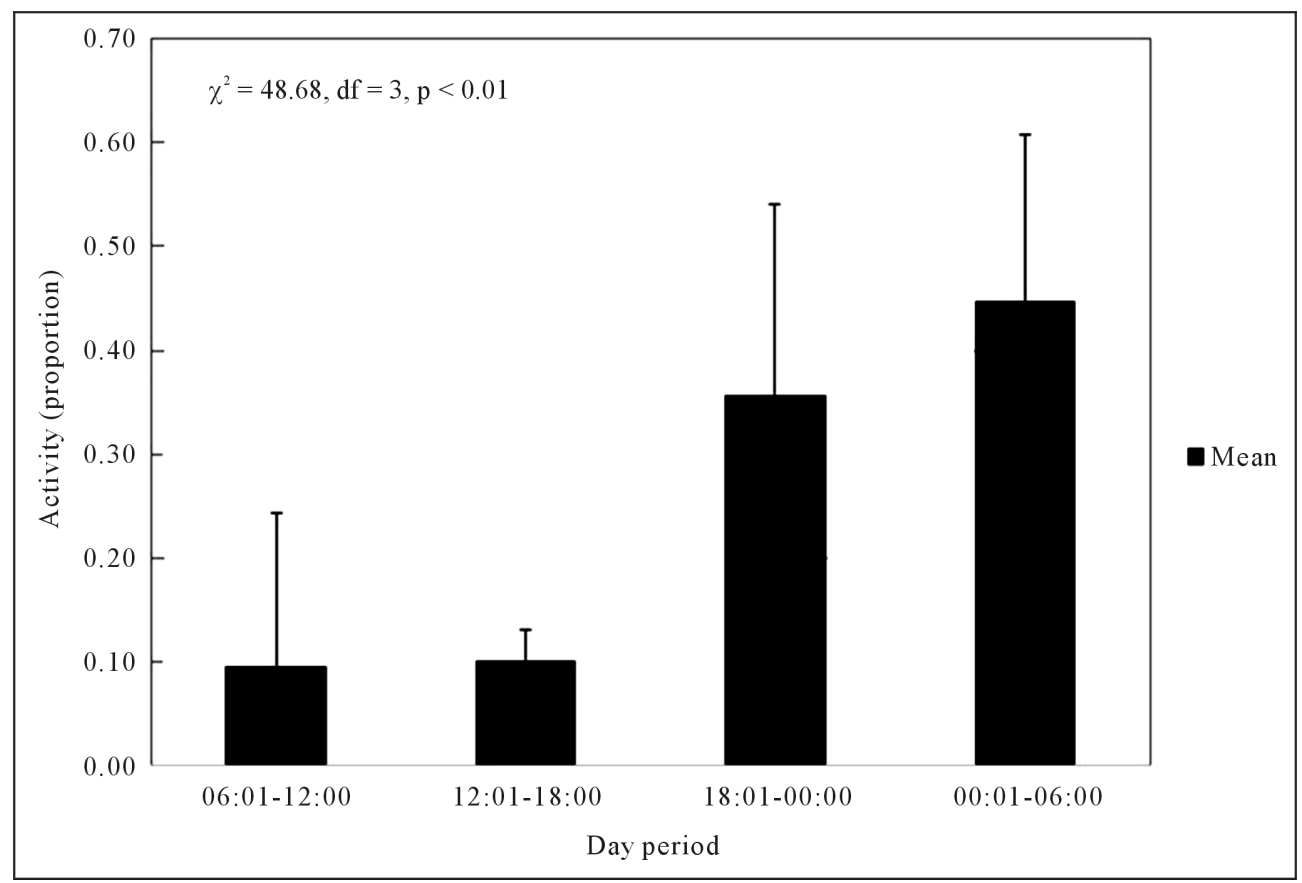

Figure 4. Temporal activity partitioning between different day periods.

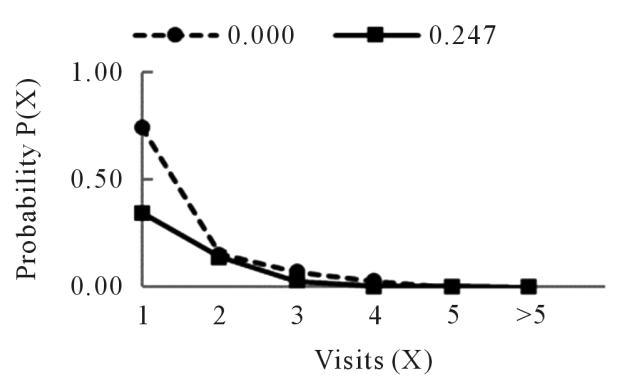

(a)

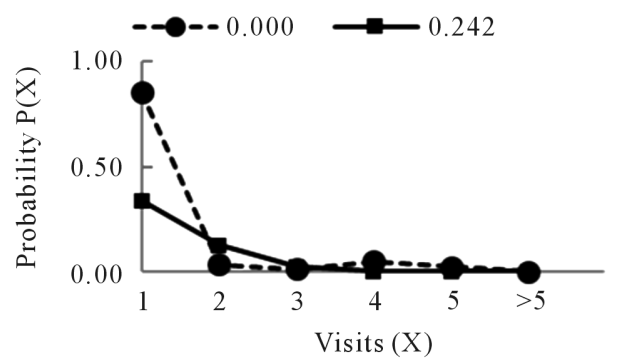

(c)

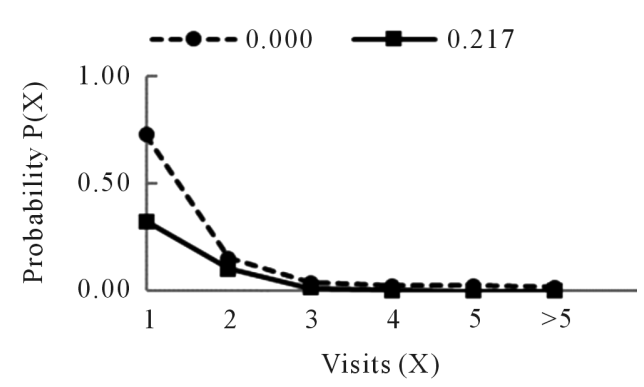

(b)

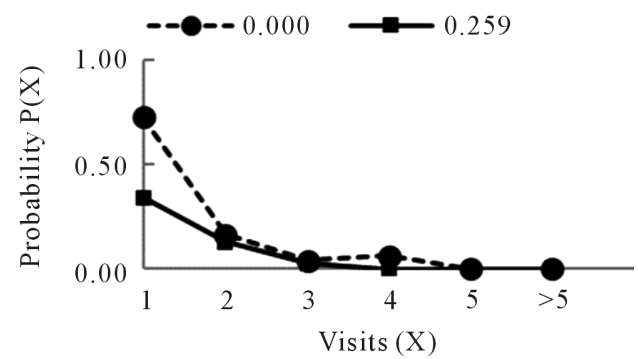

(d)

Figure 5. Probabilities of occurrence in visits to similar areas and expected random probabilities predicted from the Poisson distribution in different habitats. (a) Open: $\mathrm{I}_{\mathrm{D}}:=145.2, p=0.90$; (b) Closed: $\mathrm{I}_{\mathrm{D}}:=281.5, p=0.73$; (c) Dense: $\mathrm{I}_{\mathrm{D}}$ : dense $=136.6, p=0.24$; (d) Cleared: $\mathrm{I}_{\mathrm{D}}$ : $=48.6, p=$ 0.96 . 


\section{Discussion}

Understanding key habitat characteristics and their influence on the cheetah and its prey are both fundamental to clarify the potential effects of bush encroachment and developing effective habitat restoration and management goals of the Namibian farmland matrix. We observed differences in sighting visibility, tree/shrub density and vegetation heights between habitats and were able to confirm that the classified habitats were distinctly different from each other. Habitat characteristics including tree/shrub density and tree/shrub heights had significant negative effect on sighting visibility. This finding shows that bush encroachment has a direct impact on dependent habitat covariates such as sighting visibility. This could have negative cascading effects, specifically towards open savanna species. As an example, habitat covariates such as visibility associated with sparsely vegetated areas could be important for predator evasion by prey species including oryx, red hartebeest and warthog which rely on advance sight for flight (de Klerk, 2004). Conversely, reduced sighting visibility due to increase in tree/ shrub density and tree/shrub heights could favor browsers such as duiker, eland, and kudu, because of an abundance of browse and cover for predator evasion. Sustaining a diversity of prey species therefore, would require heterogeneous habitat patches.

In this study, species such as the warthog, oryx, scrub hare and kudu had highest overall fecal pellet presence across habitats, indicating that they were locally abundant in the study area. Scrub hare had high fecal pellet presence in the dense habitat suggesting that they might be the most available prey item in that habitat. Evidence provided by (Marker et al., 2003a) showed that a significant proportion of the cheetah's diet consisted of scrub hare.

As expected, grazer species such as oryx, red hartebeest and eland had higher presence of fecal pellets in the cleared habitat, possibly due to high available grazing. Previous studies within the study area revealed higher population densities for eland, oryx, red hartebeest and warthog in sparsely vegetated habitat. Since these prey species form an important part of the cheetah's diet (Marker et al., 2003a), selective thinning of bush could enhance prey abundance. As such, the visits by cheetah to the different habitats may be partially influenced by the abundance of these prey species, although not quantified.

Similar to previous studies (Muntifering et al., 2006); the collared male's cores showed significant distribution in the sparsely-vegetated, high -sighting visibility areas (open and cleared habitat). Areas of high encroachment were the least selected habitats for cheetahs, demonstrating the impact that bush encroachment has on habitat preference, in agreement with previous findings (Ward et al., 2000; Moleele et al., 2002; Muntifering et al., 2006; Katjiua \& Ward, 2007; Marker et al., 2008) as also seen by this study.

The most striking finding of this study is the distribution of fixes along habitat margins, which were present in all habitats, suggesting cover as an important covariate in habitat preference. Usage of habitat margins increased with sighting visibility, which indicated the need for cover in sparsely vegetated habitat. This is due to the fact that vegetated areas aid in stalking prey, relying on vegetation cover to conceal detection (Caro, 1994). Large expanse of densely vegetated core habitats was considered to be a form of degradation, which could reduce hunting efficiency, species richness, habitat heterogeneity and reduction of prey availability, with negative consequences towards population viability (de Klerk, 2004; Johnson et al., 2013). According to Murcia (1995) species are likely to converge towards habitat edges due to cascading edge effect benefits and may penetrate for some distance into surrounding habitat. The presence of the collared individuals in the different habitats might have been influenced by other proximal habitat; as availability of shade and browse along habitat margins may attract prey, which in turn attract cheetah. Given this, we conclude that associations between habitat structures are vital for a wide assemblage of native species.

Cheetahs were generally considered a diurnal species, relying on daylight for hunting and resting during the hottest part of the day (Estes, 1991). Our results showed that the collared males increased their movement activity between late afternoon early morning hours. This finding agrees with both Hayward \& Slotow (2009) and Bissett \& Bernard (2007) whom also observed similar activity patterns, ascribed to a behavioral adaptation to facilitate coexistence amongst species in the predator guild. This finding could be key to managing human-wildlife conflict by showing that increased protection such as keeping vulnerable livestock close to the homestead, the use of herders and livestock guarding dogs at all times (Marker, 2002) should be used as mitigation methods to minimize the impact of cheetah specific temporal patterns as defined in this research.

As visits to the same locations were not correlated to habitat type, revisits may be dictated by other reasons such as social interaction (e.g. scent marking), prey density or avoidance of other predators, breeding, or to de- 
fend territory, which were not quantified in this study. The wide-ranging behavior can cause an increase in conflict with farmers. Marker et al. (2008) affirmed that "wide ranging behavior have important conservation implications, given that individuals are likely to range over many farms, consequently, even a few hostile farmers could have a significant effect on the local cheetah population with these farms acting as population sinks".

Cheetahs used habitat types differently. Restoring habitat heterogeneity will be key to maintaining intact savanna ecosystems. This study indicates that a mosaic of both woody and open savanna would benefit the long-term persistence of both prey and cheetah. From an ecological standpoint bush thinning would increase grazing capacity, restore habitat sight visibility and increase the density and diversity of open savanna species (de Klerk, 2004). From a socio-economic perspective, restored habitat could potentially decrease human-wildlife conflict by increasing usable habitat for livestock. It can be assumed that higher profits by farmers will lead to higher tolerance of economic loss due to predators (Marker, 2002). A more diverse landscape encompassing different habitats could promote higher prey diversity allowing a constant supply of resources at different times of the year. This can also lead to less livestock depredation, since cheetahs are known to select wild game over domestic livestock (Marker et al., 2003a). Equally, diverse habitats could enhance the aesthetic value of the landscapes for eco-tourism.

\section{Conclusion}

This study provides important conservation data. However, it is not without limitations. A small sample of only males was used over a short time period of radio collar data. It would be useful to increase collar fix resolution to determine movement patterns throughout habitat matrices. Including females is essential in understanding differences of habitat preference between the sexes, especially regarding multiple visit data, as females typically den with young and frequent the surrounding areas (Marker et al., 2008). A strong bias exists in the capture of males than females, especially at scent marking areas (Marker et al., 2003b). Due to this potential bias, we suggest including multiple habitats and extending the study period over different seasons in order to capture a representative sample of both male and female cheetahs.

Others wishing to study similar or closely related species of the cheetah can easily duplicate the methodologies and analyses used in this study giving new insight into carnivore behavior. The findings and implications of land use management in this study will help landowners manage their livestock and farms to protect them not only from cheetah but also from other large predator species. This can help conservation of apex and keystone species, in turn aiding ecosystem sustainability. If encroachment continues to dominate the habitat matrix, loss of optimal cheetah habitat could occur. Knowing which areas are highly frequented will allow better land-use management such as preventing livestock losses, identifying ecotourism sites, assessing habitat suitability for reintroduction and configuring the scale of restoration of encroached areas. The use of edge habitat and sighting visibility raises important caveats in restoration ecology on Namibian farmlands indicating that large-scale bush clearing should not be the ultimate goal of bush encroachment restoration.

\section{Acknowledgements}

We thank the University of Exeter, the European Union and Cheetah Conservation Fund (CCF) who provided funding; the Namibian Ministry of Environment and Tourism for providing CCF's research permit; Earthwatch, and CCF interns and volunteers who helped with data collection; the Namibian farmers (Dr. Frans Indongo, Mr. Cristo Roberts, Mr. Hans Diekmann, Mr. Jean Lung and Mr. Harry Schneider-Waterberg) who allowed access to their land for data collection; and Dr. Amy Dickman, Dr. Niki Rust and Dr. Scott Turner for their input and review of our manuscript.

\section{References}

Barnard, P. (1998). Biological Diversity in Namibia: A Country-Wide Study. Namibian National Biodiversity Task Force Edn, ABC Press, Cape Town.

Ben-Shahar, R. (1992). The Effects of Bush Clearance on African Ungulates in Semi-Arid Nature Reserve. Ecological Applications, 2, 95-101. http://dx.doi.org/10.2307/1941892

Bissett, C., \& Bernard, R. T. F. (2007). Habitat Selection and Feeding Ecology of the Cheetah (Acinonyx jubatus) in Thicket Vegetation: Is the Cheetah a Savanna Specialist? Journal of Zoology, 271, 310-317. 
Brock, A., Nortje, E., \& Gaigher, I. (2003). Habitat Preference of a Local Population of Bushbuck in the Soutpansberg Mountains, South Africa. South African Journal of Wildlife Research, 33, 131-135.

Broomhall, L. S., Mills, M. G. L., \& Toit, J. T. D. (2003). Home Range and Habitat Use by Cheetahs (Acinonyx jubatus) in the Kruger National Park. Journal of Zoology, 261, 119-128. http://dx.doi.org/10.1017/S0952836903004059

Brower, J. E., Zar, H. J., \& Ende, N. J. V. (1998). Field and Laboratory Methods for General Ecology. California: McGraw-Hill Publishers.

Burke, A. (2006). Savanna Trees in Namibia: Factors Controlling Their Distribution at the Arid End of the Spectrum. Flora: Morphology, Distribution, Functional Ecology of Plants, 201, 189-201. http://dx.doi.org/10.1016/j.flora.2005.06.011

Caro, T. (1994). Cheetahs of the Serengeti Plains: Group Living of an Asocial Species. Chicago: University of Chicago Press.

de Klerk, J. N. (2004). Bush Encroachment in Namibia. Windhoek: Solitaire Press.

Durant, S., Mitchell, N., Ipavec, A., \& Groom, R. (2015). Acinonyx jubatus. The IUCN Red List of Threatened Species 2015: e.T219A50649567. http://dx.doi.org/10.2305/IUCN.UK.2015-4.RLTS.T219A50649567.en

Durant, S. M. (1998). Is Bush Country the Key to the Cheetah's Survival in Africa (pp. 14-15). Cat News: Spring.

Durant, S. M. (2000a). Living with the Enemy: Avoidance of Hyenas and Lions by Cheetahs in the Serengeti. Behavioral Ecology, 11, 624-632. http://dx.doi.org/10.1093/beheco/11.6.624

Durant, S. M. (2000b). Predator Avoidance, Breeding Experience and Reproductive Success in Endangered Cheetahs, Acinonyx jubatus. Animal Behaviour, 60, 121-130. http://dx.doi.org/10.1006/anbe.2000.1433

Durant, S. M., Kelly, M., \& Caro, T. M. (2004). Factors Affecting Life and Death in Serengeti Cheetahs: Environment, Age, and Sociality. Behavioral Ecology, 15, 11-22. http://dx.doi.org/10.1093/beheco/arg098

Eaton, R. L. (1974). The Cheetah: The biology, Ecology, and Behavior of an Endangered Species. New York: Van Nostrand Reinhold Company.

Estes, R. (1991). The Behaviour Guide to African Mammals. Oakland, CA: University of California Press.

Gros, P. M., \& Rejmanek, M. (1999). Status and Habitat Preferences of Uganda Cheetahs: An Attempt to Predict Carnivore Occurrence Based on Vegetation Structure. Biodiversity \& Conservation, 8, 1561-1583.

http://dx.doi.org/10.1023/A:1008950114827

Hayward, M., \& Slotow, R. (2009). Temporal Partitioning of Activity in Large African Carnivores: Tests of Multiple Hypotheses. South African Journal of Wildlife Research, 39, 109-125. http://dx.doi.org/10.3957/056.039.0207

Hilbert, F., Maillard, D., Fritz, H., Garel, M., Abdou, H., \& Winterton, P. (2010). Ageing of Ungulate Pellets in Semi-Arid Landscapes: How the Shade of Colour Can Refine Pellet-Group Counts. European Journal of Wildlife Research, 57, 495-503. http://dx.doi.org/10.1007/s10344-010-0458-x

Hooge, P. N., Eichenlaub, W., \& Solomon, E. (1999). The Animal Movement Program. Homepage of Alaska Biological Centre. http://alaska.usgs.gov/science/biology/spatial/gistools/animalmovementdoca.pdf

Jeltsch, F., Milton, S. J., Dean, W. R. J., \& Rooyen, N. V. (1997). Analysing Shrub Encroachment in the Southern Kalahari: A Grid-Based Modelling Approach. The Journal of Applied Ecology, 34, 1497-1508. http://dx.doi.org/10.2307/2405265

Johnson, S., Marker, L., Mengersen, K., Gordon, C., Melzheimer, J., \& Schmidt-Kuntzel, A. (2013). Modeling the Viability of the Free-Ranging Cheetah Population in Namibia: An Object Oriented Bayesian Network Approach. Ecosphere, 4, 1-19. http://dx.doi.org/10.1890/ES12-00357.1

Katjiua, M., \& Ward, D. (2007). Pastoralists' Perceptions and Realities of Vegetation Change and Browse Consumption in the Northern Kalahari, Namibia. Journal of Arid Environments, 69, 716-730.

http://dx.doi.org/10.1016/j.jaridenv.2006.11.010

Kelly, M. J., \& Durant, S. M. (2000). Viability of the Serengeti Cheetah Population. Conservation Biology, 14, $786-797$.

Kenward, R. (Ed.) (2001). A Manual for Wildlife Radio Tagging. Millbrae, CA: Academic Press.

Marker, L., Muntifering, J., Dickman, A., Mills, M., \& MacDonald, D. (2003a). Quantifying Prey Preferences for the Free-ranging Namibian Cheetah. South African Journal of Wildlife Research, 33, 43-53.

Marker, L. L. (2002). Aspects of Cheetah (Acinonyx jubatus) Biology, Ecology and Conservation Strategies on Namibian Farmlands. Ph.D. Dissertation, Oxford: University of Oxford.

Marker, L. L., Dickman, A., Wilkinson, C., Schumann, B., \& Fabiano, E. (2007). The Namibian Cheetah: Status Report. Cat News Special Issue, 3, 3-13.

Marker, L. L., Dickman, A. J., Jeo, R. M., Mills, M. G. L., \& MacDonald, D. W. (2003b). Demography of the Namibian Cheetah, Acinonyx jubatus jubatus. Biological Conservation, 114, 413-425. http://dx.doi.org/10.1016/S0006-3207(03)00069-7 
Marker, L. L., Dickman, A. J., Mills, M. G. L., Jeo, R. M., \& MacDonald, D. W. (2008). Spatial Ecology of Cheetahs on North-Central Namibian Farmlands. Journal of Zoology, 274, 226-238.

http://dx.doi.org/10.1111/j.1469-7998.2007.00375.x

Marker-Kraus, L., \& Kraus, D. (1993). The Namibian Free-Ranging Cheetah. Environmental Conservation, 21, 369-370. http://dx.doi.org/10.1017/S0376892900033750

Moleele, N. M., Ringrose, S., Matheson, W., \& Vanderpost, C. (2002). More Woody Plants? The Status of Bush Encroachment in Botswana's Grazing Areas. Journal of Environmental Management, 64, 3-11. http://dx.doi.org/10.1006/jema.2001.0486

Muntifering, J. R., Dickman, A. J., Perlow, L. M., Hruska, T., Ryan, P. G., Marker, L. L., \& Jeo, R. M. (2006). Managing the Matrix for Large Carnivores: A Novel Approach and Perspective from Cheetah (Acinonyx jubatus) Habitat Suitability Modelling. Animal Conservation, 9, 103-112. http://dx.doi.org/10.1111/j.1469-1795.2005.00008.x

Murcia, C. (1995). Edge Effects in Fragmented Forests: Implications for Conservation. Trends in Ecology \& Evolution, 10, 58-62. http://dx.doi.org/10.1016/S0169-5347(00)88977-6

Norušis, M. J. (2000). Guide to Data Analysis: SPSS 10.0. Upper Saddle River, NJ: Prentice-Hall Inc.

Rothaughe, A. (2011). Ecological Dynamics of Central Namibia's Savannahs Part 2-Bush Ecology. Agricola, No. 21, 14-24.

Southwood, T., \& Henderson, P. (2000). Ecological Methods. London: Blackwell Science Limited.

Tredoux, C., \& Durrheim, K. (2002). Number, Hypotheses \& Conclusions: A Course in Statistics for the Social Sciences. Cape Town: University of Cape Town Press.

Ward, D., Ngairorue, B. T., Apollus, A., \& Tjiveze, H. (2000). Perceptions and Realities of Land Degradation in Arid Otjimbingwe, Namibia. Journal of Arid Environments, 45, 337-356. http://dx.doi.org/10.1006/jare.2000.0647

Zimmerman, I. (2009). Causes and Consequences of Fenceline Contrasts in Namibia. Ph.D. Dissertation, Bloemfontein: University of the Free States.

\section{Submit or recommend next manuscript to SCIRP and we will provide best service for you:}

Accepting pre-submission inquiries through Email, Facebook, Linkedin, Twitter, etc A wide selection of journals (inclusive of 9 subjects, more than 200 journals)

Providing a 24-hour high-quality service

User-friendly online submission system

Fair and swift peer-review system

Efficient typesetting and proofreading procedure

Display of the result of downloads and visits, as well as the number of cited articles

Maximum dissemination of your research work

Submit your manuscript at: http://papersubmission.scirp.org/ 